ISSN 0103-9954

\title{
ANÁLISE ECONÔMICA DA INDÚSTRIA DE MADEIRAS TROPICAIS: O CASO DO PÓLO DE SINOP, MT
}

\author{
ECONOMIC ANALYSIS OF THE TROPICAL TIMBER INDUSTRY: THE COUNTY OF SINOP CASE
}

Humberto Angelo ${ }^{1}$ Gilson Fernandes da Silva ${ }^{1}$ Versides Sebastião Moraes e Silva ${ }^{2}$

\section{RESUMO}

Neste trabalho, foram analisados o comportamento e o desempenho econômico da indústria de madeiras tropicais. A área de estudo foi o pólo madeireiro de Sinop, no Estado de Mato Grosso. Foram utilizados como metodologia os fundamentos da teoria da produção para averiguar a eficiência econômica desta indústria. A consideração geral deste estudo é de que as madeireiras de Sinop apresentam um alto rendimento no processamento de toras, para os padrões da região amazônica. No entanto, a produtividade dos fatores trabalho e capital é baixa. Se as políticas no sentido de contemplar a modernização do parque industrial madeireiro integrada ao uso racional da base florestal não forem adotadas, o custo social à nação pela perda da base florestal tende a consumir os ganhos com o beneficiamento.

Palavras-chave: indústria madeireira; análise econômica; Mato Grosso.

\begin{abstract}
This work analyses the tropical wood industry, considering its performance and economic efficiency. The study area was Sinop county, in the State of Mato Grosso. The methodology used were the foundations of the theory of production to examine the performance and economic efficiency of this timber industry. The general consideration of this study is that the saw mills of Sinop present a good performance in the processing of logs considering Amazon region patterns. However, the productivity of the labour and capital factors are low. If politics in the sense of contemplating the modernization of the wood industry integrated to sustainable forest management are not adopted, the social cost can spread to society as a whole due to loss of forest that could overcome the gains with wood processing.
\end{abstract}

Key words: timber industries; economic analyses; State of Mato Grosso.

\section{INTRODUÇÃO}

A atividade florestal brasileira participa com 4\% do PIB nacional, gera milhares de empregos e é considerada uma das principais atividades para responder aos desafios da exportação. No entanto, a participação do Brasil no mercado internacional de produtos florestais é insignificante (2\%), à exceção da celulose de eucalipto, que representa $47 \%$ do mercado mundial desta commodity (SBS, 2001).

Com relação à produção de madeiras tropicais, o Brasil processa 25 milhões de metros cúbicos de toras e produz 11,2 milhões de metros cúbicos de madeiras serradas, dos quais consome 10,5 milhões, colocando-se, portanto, na liderança mundial de produção e consumo no setor (FAO, 2000).

Quanto à indústria de processamento de madeiras tropicais, é bem provável que em nenhum lugar do mundo, a indústria madeireira tenha crescido tanto quanto na região amazônica brasileira. Em 1956, somente 89 serrarias eram conhecidas na região; em 1989, este número atingiu a cifra de 2.892 (Angelo e Silva, 1998). Muitas delas são pequenas e rudimentares e operam com produção menor do que $5.000 \mathrm{~m}^{3} /$ ano. Até meados dos anos 90, cerca de 160 indústrias produziam mais de $10.000 \mathrm{~m}^{3}$ de madeira serrada. Veríssimo e Lima (1999) estimaram em 2.311 o número de serrarias na Amazônia.

A indústria madeireira na região está associada à oferta abundante de madeira de diversas espécies. Com as dificuldades cada vez maiores de se conseguir matéria-prima florestal, várias indústrias deixam de operar ou migram para novas fronteiras, o que caracteriza o perfil extrativista de um porcentual expressivo deste setor.

1. Professor do Departamento de Engenharia Florestal, Universidade de Brasília, Caixa Postal 04357, CEP 70910900, Brasília (DF). humb@terra.com.br

2. Professor do Departamento de Engenharia Florestal, Universidade Federal do Mato Grosso, CEP 70090-900, Cuiabá (MT).versides@uol.com.br

Recebido para publicação em 2/09/2003 e aceito em 20/09/2004. 
A redução do número de indústrias madeireiras já é observada em todos os Estados da Amazônia legal, exceto em Mato Grosso e Rondônia.

A evolução da indústria madeireira em Mato Grosso tem sido expressiva; de 1970 a 1997, o número de empresas passou de 99 para 860 (Veríssimo E Lima, 1999), o que coloca o Estado na liderança do quantitativo de empresas madeireiras na Amazônia.

Com a escassez da matéria-prima florestal em várias regiões da Amazônia, empresários buscam alternativas para manter suas atividades, seja por meio de adoção de técnicas de manejo florestal, seja por meio de reflorestamento com espécies potenciais para a região, entre as quais se destacam a teca, Tectona grandis L; o mogno, Swietenia macrophylla King; o pinho-cuiabano, Schizolobium amazonicum (Huber) Ducke; e outras.

Somam-se a esses fatores os custos do transporte, a carência de pesquisa e de informações técnicas, o baixo nível tecnológico da indústria, o pequeno número de espécies utilizadas, a falta de linhas de crédito para produção e o descompasso entre as atividades produtivas e os organismos oficiais normativos. Todos estes fatores afetam a oferta de produtos madeireiros nos mercados interno e externo.

De acordo com Mather (1997) e Scholz (1998), o mercado mundial da madeira está passando por mudanças profundas, que estão restringindo a competitividade dos países produtores de madeira tropical. Essas mudanças emergem de quatro áreas diferentes e têm influenciado o setor florestal nos diversos países, de forma gradual. Essas mudanças convergem ou se complementam e, às vezes, são contraditórias. As quatro áreas de transição são: a) transição no manejo florestal: da floresta nativa à floresta manejada e à plantação; b) transição na área florestada: do declínio à expansão da área florestada; c) paradigmas florestais: da floresta pré-industrial à floresta industrial e pós-industrial; e d) integração global: um sistema global de recursos florestais e uma transição industrial de norte a sul.

Desde a década de 1980, a indústria madeireira vem passando por um processo de concentração, acompanhado pela criação de uma rede internacional de localidades de produção e processamento de madeira dentro das grandes companhias transnacionais (Dudley et al., 1996; Mather, 1997). Esta concentração propicia inovações tecnológicas, que não só possibilitaram esse processo, como também "libertaram" a indústria madeireira da dependência de recursos florestais nativos e incentivaram a internacionalização através da integração vertical entre a produção e o processamento, que se transformou em um fator central de competitividade. Além disto, a integração vertical, ou seja, o estabelecimento de plantações e os investimentos em novos equipamentos de produção, requerem grandes somas de capital, inacessíveis para empresas de pequeno e médio porte.

Considerando o importante papel do Brasil no mercado de madeiras tropicais e as transformações vividas no setor industrial madeireiro, que se somam às questões ambientais, torna-se necessário conhecer melhor a indústria de beneficiamento de madeira tropical e seus efeitos sobre a Floresta Amazônica.

O conhecimento da indústria de madeiras tropicais é de suma importância para responder a uma série de questionamentos na formulação de políticas de uso racional dos recursos florestais na Amazônica brasileira.

Sendo assim, este trabalho teve como objetivos investigar e analisar o comportamento e o desempenho econômico da indústria de processamento de madeiras tropicais, tendo o pólo madeireiro de Sinop, no Estado de Mato Grosso, como a base produtora.

\section{METODOLOGIA}

\section{Local de estudo}

A cidade de Sinop foi fundada em 1974, pela Colonizadora Sociedade Imobiliária Noroeste do Paraná (Sinop), com sede na cidade de Maringá, Paraná, a partir da implantação do núcleo urbano "Gleba Celeste".

De acordo com Souza (2001), o município de Sinop possui uma área de 3.206,80 $\mathrm{km}^{2}$ e está localizado na região centro-norte do Estado do Mato Grosso, às margens da rodovia Cuiabá - Santarém (BR 
163), a $500 \mathrm{~km}$ de Cuiabá, entre os meridianos $55^{\circ} \mathrm{W}$ e $46^{\circ} \mathrm{W}$.

A população, em sua grande maioria, é originária, da Região Sul do Brasil, principalmente do Estado do Paraná e Rio Grande do Sul, e pelas estimativas do IBGE. Em 2001, o município tinha 74.761 habitantes (Governo do Mato Grosso, 2001). No entanto, $85 \%$ da população reside na zona urbana, o que faz de Sinop a quinta cidade do Estado em número de habitantes (Souza, 2001).

A região onde está localizado o município de Sinop é coberta, em sua maior extensão, pela "Floresta Estacional Amazônica Semidecidual da Meridional", com madeiras de interesse comercial, como itaúba, mescla, angelim, peroba, cedro, cambará, sucupira, entre outras. Por isto, esta região, conforme mencionado, possui grande potencial para extração de madeiras de interesse econômico, o que justifica a intensa presença da indústria madeireira no município.

\section{Fontes de Dados}

Os dados da pesquisa são de entrevistas qualitativas e quantitativas com 31 empresas madeireiras localizadas no pólo madeireiro de Sinop, visitadas nos meses de outubro e novembro de 2000. O questionário procurava identificar a características da indústria madeireira e abordava os aspectos gerais da produção, bem como a intensidade de uso dos fatores capital, trabalho e outros.

\section{Análise econômica}

Para analisar a eficácia econômica da indústria madeireira de Sinop-MT, recorreu-se à teoria da produção. Uma abordagem da produtividade dos fatores de produção na indústria madeireira, em especial os fatores capital e trabalho, à luz da teoria da produção, é encontrada no trabalho de Stone (2000).

A produção madeireira pode ser explicitada na forma Cobb-Douglas, como sendo:

$$
Q=\beta_{0} K^{\beta_{1}} L^{\beta_{2}} \varepsilon
$$

em que Q representa o volume em metro cúbico de madeira em tora processada pela indústria madeireira (IPM), ao longo do ano; K mede o valor dos bens de capitais da IPM, em reais; L representa o fator de produção trabalho, mensurado em equivalente homens, ou seja, número de trabalhadores na IPM; e é $\varepsilon$ o erro estocástico. Ajustou-se a função de produção pelo método dos mínimos quadrados ordinários.

Com a finalidade de avaliar a eficácia econométrica do modelo, foram aplicados, entre outros, os seguintes testes: a estatística F de Snedecor, visando aferir se a variável dependente é afetada por mudanças em qualquer das variáveis explicativas; e a estatística t de Student, para testar se as variáveis explicativas, individualmente, afetam de forma significativa a variável dependente.

Produtividades Médias - Dada uma função de produção $Y=f\left(X_{1}, X_{2}, \ldots \ldots . X_{\mathrm{n}}\right)$, em que $Y$ é a quantidade de produto e $X_{i}$ as quantidades dos fatores, define-se produtividade média (Pme) do iésimo fator como a relação entre a quantidade de produto e a quantidade desse fator, ou seja:

$$
\text { Pme }=\frac{Y}{X_{i}}
$$

Retorno à escala - Aumentando-se proporcionalmente todos os fatores de produção de um coeficiente $\mathrm{k}$, o aumento de produção resultante é igual a $k^{\mathrm{b} 1+\mathrm{b} 2}$. Com efeito, multiplicando-se por $\mathrm{k}$ as quantidades de fatores $\mathrm{K}$ e L na equação [1], obtém-se:

$$
b_{0}(\lambda K)^{B_{1}}(\lambda L)^{b_{2}}=b_{0} \lambda^{b_{1}+b_{2}} K^{B_{1}} L^{b_{2}}=\lambda^{b_{1}+b_{2}} \cdot Q
$$

Da expressão [3], é fácil concluir que retornos de escala na função Cobb-Douglas são medidos pela soma dos parâmetros $b_{i}$ (Barbosa, 1985). Os seguintes casos são possíveis:

a) $\sum_{i=1}^{n} b_{i}>1$, retornos crescentes de escala; 
b) $\sum_{i=1}^{n} b_{i}=1$, retornos constantes de escala; e

c) $\sum_{i=1}^{n} b_{i}<1$, retornos decrescentes de escala.

Somando, então, os coeficientes de regressão ou as elasticidades parciais de produção de uma função de produção Cobb-Douglas, tem-se o coeficiente de escala, que indica a porcentagem de aumento na produção, se todos os fatores forem aumentados em dada porcentagem.

Elasticidades de produção - As elasticidades medem as variações porcentuais na produção $(Y)$, causadas por variações nos fatores $X_{i}$. No caso em que todos os fatores envolvidos no processo variem na mesma proporção, motivando idêntica variação porcentual na produção, tem-se a elasticidade total de produção (Ep) e, quando se tem a variação de um só fator, mantendo-se os outros constantes, tem-se a elasticidade parcial de produção $\left(\mathrm{EP}_{\mathrm{i}}\right)$, que é tratada nesta parte.

$$
E p_{i}=\frac{\partial Y}{\partial X i} \frac{X i}{Y}
$$

Em que: $E p_{i}=$ elasticidade parcial de produção do iésimo fator; $\frac{\partial Y}{\partial X i}=$ derivada da produção em relação ao iésimo fator; $Y=$ quantidade de produção; $X_{i}=$ quantidade do iésimo fator, e $i=1,2, \ldots n$.

Produtividade marginal e uso dos recursos - Entende-se por produtividade marginal (Pma) de um fator o acréscimo de produto que se obtém quando se emprega uma unidade a mais desse fator, mantendo-se constantes as quantidades dos demais fatores, de acordo com Simonsen (1968).

Em termos de cálculo diferencial, essa definição implica a derivada parcial do produto em relação ao fator, ou seja:

$$
P m a_{x_{i}}=\frac{\partial Y}{\partial X_{i}}
$$

Em que: $P m a_{x_{i}}=$ produtividade marginal de $X i$, em um determinado ponto; $\frac{\partial Y}{\partial X_{i}}=$ derivada da função de produção $Y$ em relação ao fator $\mathrm{i}$; e $i=1,2,3 \ldots . . . n$.

No presente trabalho, a produtividade marginal foi calculada ao multiplicar o coeficiente de regressão (bi) pelo produto médio do fator considerado.

Segundo Heady e Dillon (1966), esta é a melhor maneira de avaliar as produtividades marginais dos fatores na função de Cobb-Douglas. O produto marginal assim calculado é aquele que corresponde ao ponto médio do fator considerado.

Para Tollini (1969), as estimativas das produtividades marginais, com os fatores em médias geométricas, conduzem a menores erros quando sua variância é calculada.

Taxa Marginal de Substituição - A taxa marginal de substituição técnica de trabalho (L) por capital (K) $\left(\mathrm{TMS}_{\mathrm{lk}}\right)$ refere-se à quantidade de $\mathrm{K}$ que a firma reduz pelo aumento da quantidade de $\mathrm{L}$, sem alterar a quantidade produzida. A $\mathrm{TMS}_{\mathrm{lk}}$ é também igual ao produto marginal do trabalho $\left(P m g_{l}\right)$ dividido pelo produto marginal do capital $\left(P m g_{k}\right)$. Matematicamente, tem-se que:

$$
T M S_{L K}=\frac{P m g_{l}}{P m g_{k}}
$$




\section{RESULTADOS E DISCUSSÃO}

\section{Caracterização da indústria madeireira de Sinop}

As madeireiras pesquisadas instalaram-se no pólo madeireiro de Sinop entre 1975 e 1996 . Na amostra analisada, 93\% são serrarias e 7\% são laminadoras.

Matéria-prima florestal - A Tabela 1 apresenta a participação de cada espécie na demanda total, os preços pagos pela madeira colocada no pátio e o rendimento para cada espécie, para produção de lâminas e serrados.

As espécies mais laminadas são a amescla, o angelim-saia e a farinha-seca. O rendimento médio da produção de lâmina está em torno 61,47\%, valor este superior ao encontrado por Vidal et al. (1997), que verificaram rendimento de $39 \%$ para as madeireiras do Estado do Pará. No período de outubro a novembro de 2000, o custo de laminação por metro cúbico de madeira para laminação colocada no pátio da indústria variava de $\mathrm{R} \$ 40,00$ a $\mathrm{R} \$ 63,00$.

TABELA 1: Consumo, preço e rendimento das toras destinadas à produção de lâminas e serrados por espécie, no pólo madeiro de Sinop, MT.

TABLE 1: Demand, price and revenue of the logs destined to the production of veneer and sawnwood by species, in the county of Sinop, MT.

\begin{tabular}{|c|c|c|c|c|c|c|c|}
\hline \multicolumn{2}{|c|}{ Espécie } & \multicolumn{3}{|c|}{ Laminação } & \multicolumn{3}{|c|}{ Serraria } \\
\hline Nome Comum & Nome Científico & $\begin{array}{l}\text { Consumo } \\
(\%)\end{array}$ & $\begin{array}{l}\text { Preço no } \\
\text { Pátio } \\
\left(\mathrm{R} \$ / \mathrm{m}^{3}\right) \\
\end{array}$ & $\begin{array}{l}\text { Rendimento } \\
(\%)\end{array}$ & $\begin{array}{l}\text { Consumo } \\
(\%)\end{array}$ & $\begin{array}{l}\text { Preço no } \\
\text { Pátio } \\
\text { (R\$) }\end{array}$ & $\begin{array}{c}\text { Rendimento } \\
(\%)\end{array}$ \\
\hline $\begin{array}{l}\text { Amescla ou } \\
\text { Morcegueira }\end{array}$ & $\begin{array}{l}\text { Trattinnickia } \\
\text { burseraefolia } \\
\text { (Mart.) Willd }\end{array}$ & 91,50 & 65,00 & 62,60 & - & - & 60,00 \\
\hline $\begin{array}{l}\text { Angelim- } \\
\text { pedra }\end{array}$ & $\begin{array}{l}\text { Dinizia excelsa } \\
\text { Ducke }\end{array}$ & - & - & - & 4,28 & 60,25 & 55,90 \\
\hline Angelim-saia & $\begin{array}{l}\text { Parkia pendula } \\
\text { (Willd.) Benth. ex } \\
\text { Walp }\end{array}$ & 6,46 & 63,00 & 56,00 & 0,03 & 60,00 & 55,00 \\
\hline Cambará & Vochysia sp & - & - & - & 17,63 & 47,00 & 54,30 \\
\hline Canelão & $\begin{array}{l}\text { Nectandra cuspidata } \\
\text { Nees }\end{array}$ & - & - & - & 0,85 & 50,00 & 57,50 \\
\hline Cedrinho & Erisma uncinatum & - & - & - & 43,24 & 56,43 & 56,70 \\
\hline Champanhe & $\begin{array}{l}\text { Dipteryx odorata } \\
\text { (Aubl.) Willd }\end{array}$ & - & - & - & 0,09 & 60,00 & 55,20 \\
\hline Farinha-seca & Albizia hasslerii & 1,92 & 60,00 & 56,00 & - & - & 52,50 \\
\hline Garapeira & $\begin{array}{l}\text { Apuleia leiocarpa } \\
\text { (Vogel) J.F.Macbr }\end{array}$ & - & - & - & 0,63 & 56,00 & 45,40 \\
\hline Itaúba & $\begin{array}{l}\text { Mezilaurus itauba } \\
\text { (Meisn.) Taub. ex } \\
\text { Mez }\end{array}$ & - & - & - & 12,60 & 75,00 & 49,10 \\
\hline Cupiúba & Goupia glabra Aubl & - & - & - & 20,56 & 56,00 & 61,90 \\
\hline Outras & Outras & - & $\begin{array}{c}40,00 \mathrm{a} \\
54,00\end{array}$ & - & 0,09 & 55,00 & 58,30 \\
\hline
\end{tabular}

Fonte: Dados da pesquisa de campo.

A peroba-cupiúba, o cedrinho, o cambará, o canelão e a itaúba são as espécies demandadas para produção de serrados. Essas espécies representam 91\% do consumo total. O aproveitamento médio das toras na serraria, de acordo com os empresários, está em torno de 54,85\%, valor também superior ao encontrado por Vidal et al. (1997) para o pólo madeireiro de Paragaminas-PA. Com relação ao rendimento por espécie, o maior grau de aproveitamento fica para a cupiúba. 
O valor encontrado para o rendimento, considerado alto para os padrões da indústria regional, pode ser explicado pelo pequeno número de espécies processadas e pela abundância do recurso florestal, o que permite selecionar matéria-prima de melhor qualidade.

Os preços pagos pela madeira, destinada à produção de serrados, colocada no pátio variam de $\mathrm{R} \$ 47,00$, para o cambará, a $\mathrm{R} \$ 75,00$, para a itaúba.

O consumo diário de toras está em torno de $48 \mathrm{~m}^{3}$; a amplitude do consumo é de 8 a $100 \mathrm{~m}^{3} /$ dia. Observou-se que $72 \%$ das empresas processam menos de $56 \mathrm{~m}^{3}$ de toras/dia.

Verificou-se que $96 \%$ das empresas utilizam o método geométrico na aferição do volume de toras. Os valores médios dos diâmetros mínimo, máximo e médio para as toras beneficiadas foram, respectivamente, 41,125 e $69 \mathrm{~cm}$. O comprimento das toras variou de 2,50 a 9,75 m.

A oferta de madeira tem origem em florestas de terceiros, para $71 \%$ das empresas. Este resultado demonstra que a integração indústria/floresta ainda não é uma prática generalizada, além de evidenciar uma independência entre o processamento e a gestão da base florestal. Indica também que parte desta madeira pode ter origem no desmatamento.

Em média, as empresas distam 163,6 km da floresta, devendo-se destacar que, para 85,7\% delas a matéria-prima florestal não dista mais que $208 \mathrm{~km}$. O custo médio do frete das toras da floresta à indústria é em torno de $\mathrm{R} \$ 10,94 / \mathrm{km}$.

Preço da madeira em pé - A Tabela 2 apresenta o preço médio da madeira em pé para as espécies demandadas pelo pólo madeireiro de Sinop. O preço do metro cúbico varia entre $R \$ 15,00$ e R $\$ 21,33$ para serraria e entre $\mathrm{R} \$ 15,00$ e $\mathrm{R} \$ 21,00$ para laminação.

Para laminação, a amescla é a madeira mais cara; já para a serraria, o maior valor fica para a itaúba.

TABELA 2: Preço da madeira em pé para serraria e laminação, Sinop, MT.

TABLE 2: Wood stumpage price for sawmill, in the county of Sinop, MT.

\begin{tabular}{l|c|c}
\hline \multirow{2}{*}{ Espécie } & \multicolumn{2}{|c}{ Preço da Madeira em Pé $\left(\mathrm{R} \$ / \mathrm{m}^{3}\right)$} \\
\cline { 2 - 3 } & Serraria & Laminação \\
\hline Amescla & - & 21,00 \\
Angelim-pedra & 15,00 & - \\
Angelin-saia & - & 15,00 \\
Cambara & 14,83 & - \\
Canelão & 15,00 & - \\
Cedrinho & 19,57 & - \\
Champanhe & - & - \\
Farinha-seca & - & 15,00 \\
Garapeira & 15,00 & - \\
Itaúba & 21,33 & - \\
Peroba/Cupiuba & 15,00 & - \\
\hline
\end{tabular}

Fonte: Dados da pesquisa de campo.

Limitaçães na produção - Cerca de 90\% das empresas apresentaram dificuldade em obter matériaprima. As queixas mais numerosas referem-se à parte legal: 55\% reclamaram da documentação, liberação de projetos ou autorização; $15 \%$ remeteram às dificuldades para o conjunto documentação, chuvas, preços $\mathrm{e}$ distância; e 15\% citaram a chuva ou a distância. Reclamações quanto à escassez de madeira, à heterogeneidade do material e ao fornecedor foram também mencionadas.

Já para a estocagem de toras, $83 \%$ da empresas apresentaram problemas, tendo sido os mais mencionados a falta de capital e a degradação por insetos e, ou fungos.

Quanto ao beneficiamento, $98 \%$ afirmaram não ter problemas com o desdobro primário e secundário; $67 \%$ têm problemas para estocarem o produto beneficiado; e, em média, $56 \%$ da produção é elaborada sob encomenda. 
Quanto aos bens de capital, para 75\% das madeireiras o seu valor não ultrapassa 814 mil reais, o que resulta em um faturamento anual médio de $\mathrm{R} \$ 2.965 .909,09$.

Das empresas amostradas, 44\% não possuíam geradores próprios, portanto dependem de energia elétrica. Das que possuíam, os geradores tinham potência média de $500 \mathrm{HP}$ (amplitude de 320 a $800 \mathrm{HP}$ ) e de $135 \mathrm{Kwh}$ (amplitude de 135 a 800). O consumo médio de energia está em torno de $27.684,58 \mathrm{Kwh} / \mathrm{mês,} \mathrm{o}$ que implica um custo médio mensal de energia da ordem de $\mathrm{R} \$ 7.367,73$.

\section{Análise econômica}

Os resultados estatísticos do ajuste da função de produção estão na Tabela 4 . Cerca de $65,33 \%$ da produção é explicada pelos fatores capital e trabalho na indústria madeireira de Sinop-MT. Os parâmetros estimados são significativos a $5 \%$ de probabilidade, pelo teste de Student, e o erro-padrão residual é relativamente baixo.

TABELA 3: Estatísticas da função de produção.

TABLE 3: Statistics of the production function.

\begin{tabular}{lcccc}
\hline Variáveis & Coeficientes & Desvio-Padrão & T de Student & Probabilidade \\
\hline Intercpto & 7,21420 & 1,461057 & 4,93766 & 0,001138 \\
Capital (LnK) & 0,57289 & 0,191299 & 2,99475 & 0,017209 \\
Mao de obra (LnL) & $-1,57137$ & 0,405625 & $-3,87394$ & 0,004715 \\
\hline
\end{tabular}

Em que: $\mathrm{R}^{2}=0,653, \mathrm{~F}(2,8)=7,53$ e $\mathrm{EPR}=0,45$.

Produtividades Médias - Na Tabela 5, estão listadas as produtividades médias, calculadas por meio de médias geométricas, para os fatores mão-de-obra e capital envolvidos na produção madeireira.

TABELA 4: Produtividade média dos recursos empregados na indústria madeireira.

TABLE 4: Average productivity of production employees in sawmill factors.

\begin{tabular}{l|c}
\hline Fator de Produção & Produtividade Média \\
\hline Capital (K) em $\mathrm{m}^{3}$ tora ano/reais & 0,01 \\
Trabalho (L) em m ${ }^{3}$ tora ano/equivalente homem & 116,35 \\
Produção (Q) em m ${ }^{3}$ tora ano/UPM & $7.562,59$ \\
Rendimento (\%) & 54,85 \\
\hline
\end{tabular}

Em que: UPM = unidade de processamento de madeira.

Dos resultados encontrados, pode-se aferir que as produtividades dos fatores analisados são baixas. Com relação ao fator mão-de-obra, considerando 250 dias trabalhados/ano, a produtividade diária da mãode-obra está em torno de $0,47 \mathrm{~m}^{3}$.

TABELA 5: Retorno à escala dos fatores capital e trabalho.

TABLE 5: Scale return of capital and labour factors.

\begin{tabular}{lc}
\hline Variáveis & Coeficiente \\
\hline Capital (LnK) & 0,57289 \\
Trabalho (LnL) & $-1,57137$ \\
\hline Total & $-0,99848$ \\
\hline
\end{tabular}

Quanto ao fator capital, o investimento médio para o processamento de toras é de $\mathrm{R} \$ 1,00$ para cada $100 \mathrm{~m}^{3}$ de toras beneficiadas.

As Figuras 1 e 2 mostram o comportamento da produtividade dos fatores em relação ao tamanho da empresa. Para ambos os fatores, a produtividade é crescente, ou seja, ela aumenta à medida que a sua capacidade de processamento aumenta até por volta de 6-7 $\mathrm{mil}^{3}$ de toras/ano.

Esse resultado indica que as empresas com capacidade de processamento inferior a 6-7 mil $\mathrm{m}^{3} \mathrm{de}$ toras/ano estão alocando de forma ineficiente os seus recursos produtivos trabalho e capital. 


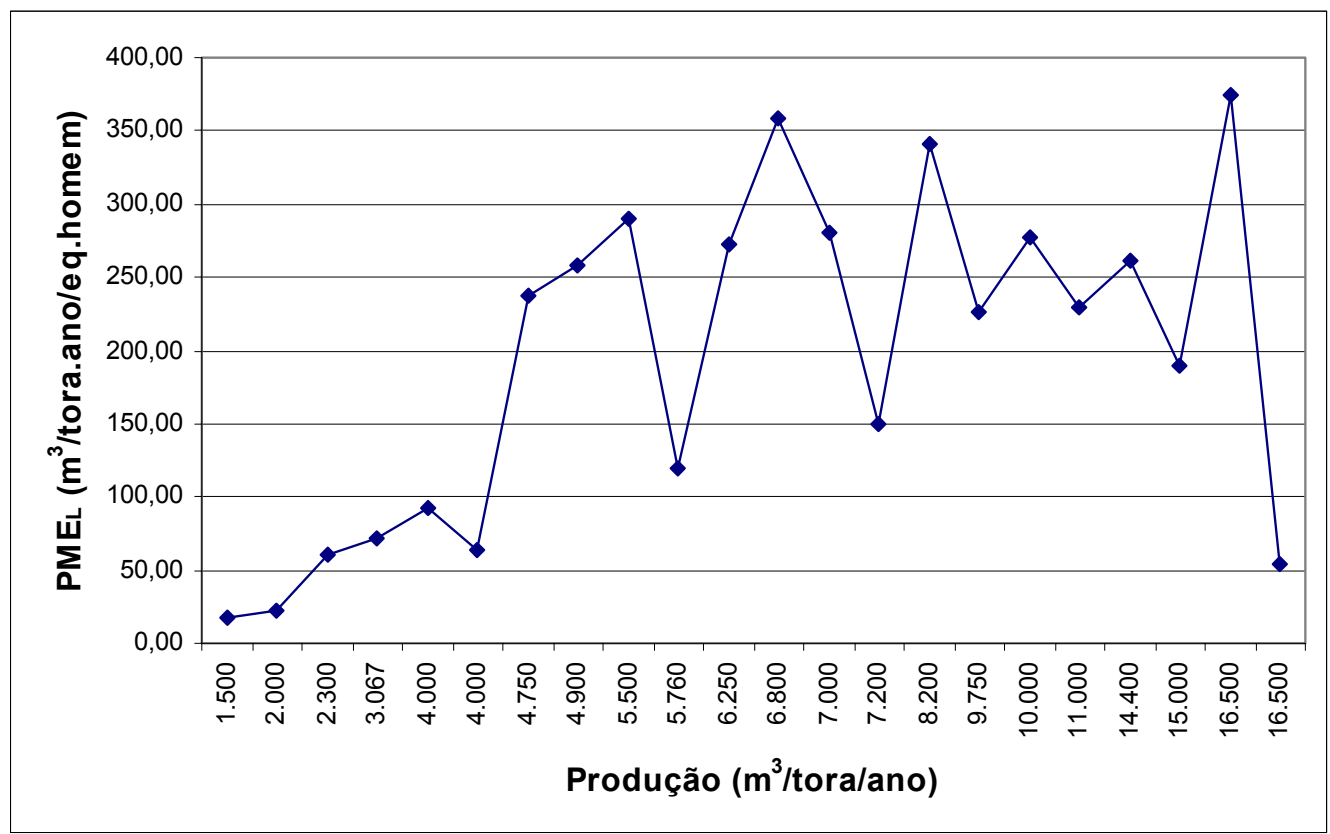

FIGURA 1: Produtividade da mão-de-obra em relação ao tamanho da madeireira.

FIGURE 1: Labor productivity in relation to the size of the sawmill.

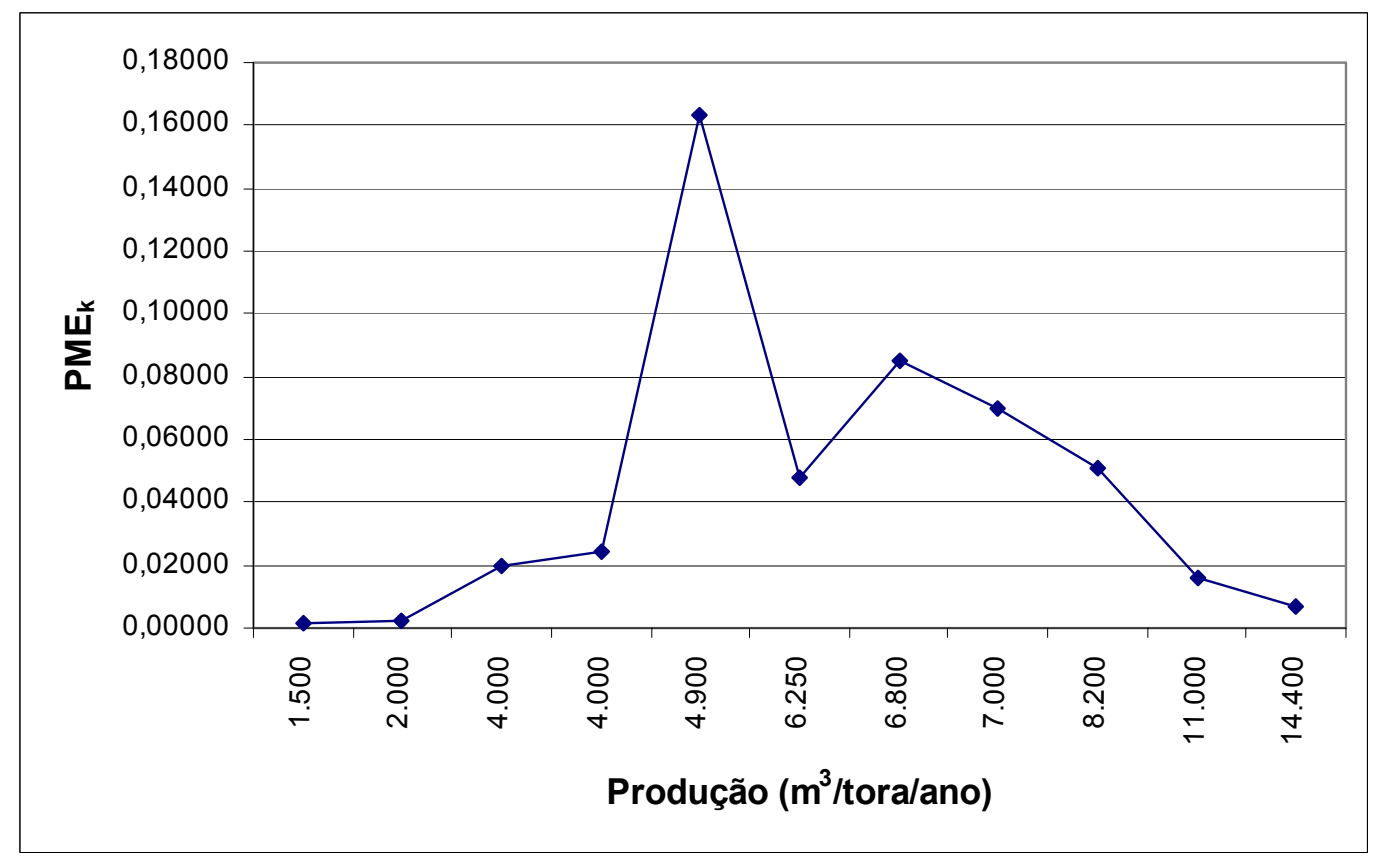

FIGURA 1: Produtividade do capital em relação ao tamanho da madeireira.

FIGURE 1: Capital productivity in relation to the size of the sawmill.

Retorno à escala - Na Tabela 6 está o valor do coeficiente de escala. Nota-se que ele é menor que a unidade e é negativo, o que indica que se tem retorno à escala decrescente. Assim, a longo prazo, ao dobrar a utilização dos recursos empregados na produção de madeira tem-se a redução em dobro de produção.

Em virtude desse retorno à escala decrescente, recomenda-se que a indústria de base florestal de Sinop adote ações que resultem no aumento da produtividade da mão-de-obra. Medidas simples, como a qualificação mão-de-obra por meio de treinamento, podem ser a resposta a esta situação.

Elasticidades de Produção - Na função de produção de Cobb-Douglas, a elasticidade do iésimo 
recurso é dada diretamente pelo seu coeficiente de regressão (bi). Para que a utilização do iésimo recurso esteja no estágio racional de produção ( $2^{\underline{0}}$ estágio), é necessário que o coeficiente seja positivo e menor que a unidade; se for maior que a unidade, sua utilização se encontra no primeiro estágio de produção (irracional); e, caso seja negativo, encontra-se no terceiro estágio (irracional), desde que a função seja homogênea de grau 1.

No presente estudo, considera-se que as outras variáveis sejam mantidas constantes. Portanto, têm-se as seguintes possibilidades, com bases nos resultados obtidos e apresentados na Tabela 7.

TABELA 6: Elasticidade de produção dos fatores capital e trabalho.

TABLE 6: Elasticity of production of capital and labour factors.

\begin{tabular}{lc}
\hline Fator de Produção & Elasticidade de Produção \\
\hline Capital (K) & 0,57289 \\
Mão-de-obra (L) & $-1,57137$ \\
\hline
\end{tabular}

TABELA 7: Produtividade marginal dos fatores capital e trabalho.

TABLE 7: Marginal productivity of capital and labour factors.

\begin{tabular}{lc}
\hline Fator de Produção & Produtividade Marginal \\
\hline Capital (K) & 0,007 \\
Trabalho (L) & $-182,825$ \\
\hline
\end{tabular}

O aumento de $10 \%$ em investimento no fator capital determina incremento na produção de 5,73 \%, enquanto o aumento de $10 \%$ no fator mão-de-obra resulta na redução de $15,71 \%$ na produção madeireira. Observa-se que a indústria madeireira de Sinop está empregando o fator capital racionalmente ( $2^{\circ}$ estágio), ao passo que o fator mão-de-obra está sendo empregado irracionalmente, no $3^{\circ}$ estágio.

Logo, sugere-se à indústria madeireira de Sinop a manutenção do fator capital nos níveis atuais e a redução do fator de produção mão-de-obra.

Produtividade marginal e uso dos recursos - Na Tabela 8, está o valor do produto marginal dos fatores mão-de-obra e capital empregados na produção madeireira. Os valores encontrados confirmam a irracionalidade no uso do fator mão-de-obra. O aumento de uma unidade a mais do fator mão-de-obra resultaria em decréscimo da produção. A ordem de grandeza estaria em torno de $183 \mathrm{~m}^{3}$ de toras a menos processadas por ano.

Para o fator capital, o aumento nos investimentos de bens de capitais de $\mathrm{R} \$ 1,00$ resulta em um incremento de apenas $0,007 \mathrm{~m}^{3}$ de tora processada. O Pmg do fator capital já se encontra muito próximo de zero, o que significa que as madeireiras utilizam esse fator muito próximo do limite superior do estágio racional de produção, ou seja, a intensidade de uso deste fator está gerando o máximo de produção física esperada do fator.

Esse resultado evidencia que o aumento da produção desta indústria implica a modernização do parque industrial.

Taxa Marginal de Substituição - É também igual ao produto marginal do trabalho dividido pelo produto marginal do capital. Matematicamente, tem-se que:

$$
T M S_{L K}=\frac{P m g_{l}}{P m g_{k}}=\frac{182,825}{0,07}=27.662,23
$$

Esse valor significa que, para substituir uma unidade do fator mão-de-obra, é preciso o investimento de $\mathrm{R} \$ 27.662,23 \mathrm{em}$ bens de capitais no processo produtivo de madeira. Em outras palavras, para gerar um novo emprego na indústria de processamento de madeira de Sinop, há a necessidade de investir o equivalente a R $\$ 27.662,23$ em bens de capital. 


\section{CONCLUSÕES}

Este estudo sobre a indústria de madeiras tropicais indica vários pontos importantes sobre a produção, o desempenho e a produtividade dos recursos nas madeireiras de Sinop, Estado do Mato Grosso:

O rendimento no processamento de toras é de $54,85 \%$.

A produção de madeiras tropicais responde às variações na alocação dos fatores trabalho e capital, em uma ordem de grandeza em que $65 \%$ da produção é explicada pela alocação desses dois recursos.

Os valores encontrados para a elasticidade de produção indicam que o fator mão-de-obra está sendo empregado irracionalmente, enquanto o fator capital está sendo utilizado racionalmente. Há a necessidade de aumentar a produtividade do fator trabalho.

Para geração de um emprego na indústria madeireira de Sinop, há a necessidade de investimento de capital na ordem de 27,6 mil reais.

Com base na análise gráfica, conclui-se que o tamanho econômico mínimo de uma indústria madeireira equivale à capacidade de beneficiar $7 \mathrm{mil} \mathrm{m}^{3} /$ tora/ano, pois, nesta dimensão, elas estão trabalhando no máximo da produtividade dos fatores capital e trabalho.

A baixa produtividade dos fatores capital e trabalho empregados no processamento da madeira confirmam a hipótese postulada de que o fácil acesso ao recurso florestal ainda é a grande fonte de oferta de madeira da região no período estudado, pois $71 \%$ das madeireiras pesquisadas obtêm sua matéria-prima de florestas de terceiros.

Medidas simples, como a manutenção do fator capital nos níveis atuais a curto prazo, aliada ao treinamento da mão-de-obra, visando aumentar a sua produtividade, resultariam em uma melhora no desempenho da indústria madeireira de Sinop.

A consideração geral deste estudo é de que as madeireiras de Sinop apresentam um rendimento no processamento de toras alto para os padrões da região amazônica. No entanto, a produtividade dos fatores trabalho e capital é baixa. Se políticas no sentido de contemplar a modernização do parque industrial madeireiro integrada ao uso racional da base florestal não forem adotadas, o custo social à nação pela perda da base florestal tende a consumir os ganhos com o beneficiamento.

Por fim, é interessante levantar sugestões para novas pesquisas. Recomenda-se questionar como estabelecer mecanismo para modernizar a indústria madeireira amazônica e estudar os efeitos da expansão da indústria de madeiras tropicais e seus respectivos impactos na floresta tropical no Estado de Mato Grosso.

\section{REFERÊNCIAS BIBLIOGRÁFICAS}

ANGELO, H; SILVA, D. A. As exportações brasileiras de mogno (Swietenia macrophylla, King). Revista Árvore, v. 22, n. 1, p. 113-121, 1998.

BARBOSA, F. H. Microeconomia: teoria, modelos econométricos e aplicações à economia brasileira. Rio de Janeiro: IPEA/INPES, 1985. $556 \mathrm{p}$.

DUDLEY, N.; JEANRENAUD, J. P.; SULLIVAN, F. Bad harvest? the timber trade and the degradation of the world's forests. Londres: Earthscan, 1996.

FAO Forestry . Disponivel em: < http://www.fao.it/ $>$ Acesso em: 2000.

GOVERNO DO ESTADO DO MATO GROSSO, Disponivel em: <http://www.sinop.mt.gov.br $>$ Acesso em: 12 ago. 2001.

HEADY, E. O.; DILLON, J. L. Agricultural production function. Ames, Iowa: Iowa State University Press, 1966. $667 \mathrm{p}$.

MATHER, A. South-North Challenges in Global Forestry, Helsinki: UNU/WIDER Working Paper noํ145. 1997.

SBS - Disponivel em: <http://www.sbs.org.br $>$. Acesso em : out. 2001

SCHOLZ, I. Comércio, meio ambiente e competitividade: o caso da indústria madeireira do Pará. 1998. 68 p. Dissertação (Mestrado) - Programa de Bolsas Instituto Rio Branco/BID, Brasilia, 1998.

SIMONSEN, M. H. Teoria microeconômica. Rio de Janeiro, FGV, 1968. vol II. 
SOUZA, E. A. Colonizadora Sinop. Disponivel em: http://www.sinop.com.br/. Acesso em: 26 abr. 2001.

STONE, S. W. Tendências econômicas da indústria madeireira no Estado do Pará. Belém: IMAZON, 2001. 37 p. (Série Amazônia, 17)

TOLLINI, H. Actual and optimal use of fertilizer. 1969. 96 p. (Thesis (Ph.D.) - North Carolina State University, 1969.

VERÍSSIMO, A.; LIMA, E. Pólos de exploração madeireira na Amazônia. Belém: IMAZON. 1999. (manuscrito)

VIDAL, E.; GERWING, J; BARRETO, P.; JOHNS, J. Redução de desperdícios na produção de madeira na Amazônia. Belém : IMAZON, 1997. 18 p. (Série Amazônia, 5) 